\title{
Liber Pater epigráfico en Hispania: Textos y contexto religioso
}

\author{
Oscar Garcia Sanz
}

INTRODUCCIÓN: LA EPIGRAFIA COMO MÉTODO DE ESTUDIO

Entre las distintas fuentes utilizadas para mi estudio sobre Baco son las epigráficas las que más han atraído mi atención. Primeramente por pertenecer a mi ámbito filológico más directamente que otras de expresión solamente iconográfica. También por comprobar la riqueza de información que recogen los epígrafes, considerados a menudo como ciencia auxiliar, hermana pobre y desheredada de la Filología y no como un testimonio escrito de la vida del pasado, que se está revelando como una fuente en muchos sentidos más objetiva, real y desprovista de intencionalidad y efectismo que la Literatura. A todo ello se añade que el conocimiento que nos transmite es más individuado. Conocemos a través de elia no la teoría sobre el patriciado, el culto al Emperador o la vida de un liberto, sino el historial del patricio $X$, sus cargos y relaciones sociales, el grupo que dedica un ara a AUGUSTO y en qué circunstancias, y los sentimiento del Dueño $X$ hacia su esclavo o liberto $X$. $Y$ de la suma $y$ comparación de estas particularidades sí podemos ofrecer una teoría fiable, que pueda contrastarse y completarse con la ofrecida por las fuentes literarias y arqueológicas.

Y si esto lo llevamos al campo de la Religión romana, es la Epigrafía la que más puede hablarnos de la entidad y del ser de los dioses para sus dedicantes (fórmula de divinidad), siempre singulares. También del tipo de culto que les tributaban, del arraigo del mismo en una población e incluso de la sinceridad que movía su ofrenda (fórmula de dedicación y tipo de soporte). $\mathrm{Y}$ al observar la caracterización que la persona hace 
en su dedicación no es dificil hacer una radiografía sobre condición social, cargos y familia (onomástica).

En el caso del dios que nos ocupa, es posible que sea la fuente de información más controvertida, pues los resultados que arroja abligan a revisar mucho de lo dicho sobre Baco en Hispania.

Comenzando por el "número de epígrafes», que ha ido desde los siete de Bruhl en Liber Pater (1953), los "moins d'une dizaine" de Etienne en Fouilles de Conimbriga, II (1976), los nueve de Vázquez y Hoys en La Religión romana (Tesis de 1974, publicado en 1982), que no incrementa en 1987 en "La religiosidad" y las veintiocho de Montaña Frontera (seis muy poco fiables) que cita sin estudio ni fuentes $\mathrm{J}$. Corell en El culto a Liber Pater (1988). En mi Catálogo * recojo 15 de Sagunto más 21 del resto de la península, que hacen un total de 36 , lo cual forma un Corpus lo suficientemente variado y numeroso para poder extraer de él algunas conclusiones que permitan acercarnos a esta figura. De este modo ya no podrá hablarse de que cada una de estas inscripciones sean «un des rares documents concernant le culte rendu dans la Peninsule Ibérique a l'une des divinités les plus considérables du Panthéon grécoromain" '.

Otros aspectos de la controversia han sido la unidad en la "denominación de la divinidad" como LIBERO o LIBERO PATRI, ignorándose sistemáticamente el BACCHUS y mucho más el DIONYSUS en dativo. También sorprende la gran ausencia de estos epígrafes en zonas tan romanizadas, excavadas y ricas en otros testimonios del dios como Tarraco y Emerita, además de Barcino, Clunia, Hispalis, Corduba, Caesaraugusta, Gades, Astigi, que no cuentan con un solo epígrafe. Solo Itálica, con dos epigrafes, y Asturica, Legio VII, Castulo, Carthago, Olisipo y Conimbriga con uno cada una son centros importantes; los demás han aparecido en zonas muy poco conocidas por su romanidad o en núcleos rurales.

De todo esto me ha sido necesario emprender un estudio que conduzca a una cierta explicación.

* En la última parte puede hallarse 1) un Catálogo abreviado de las piezas recogidas en mi tesis doctoral Baco en Hispania. Economia y Religión, a través de las fuentes epigráficas, arqueológicas y literarias, que se ofrecen en dos cuadros-resumen de las inscripciones por conventus destacando las de Montaña Frontera de Sagunto; en el comentario se alude a la numeración seguida en el Catálogo. 2) Mapa de la distribución de los epígrafes y 3$)$ las referencias bibliográficas completas, citadas a pie de página de modo abreviado.

1 VV.AA. (Etienne, R., et alt.) Fovilles de Conimbriga, II, pág. 33, núm. 101. 


\title{
ESTUDIO POR PROVINCIAS
}

\author{
BAETICA
}

Tres son las inscripciones, de hallazgo antiguo por más datos, que presenta esta provincia: C/L II, 1108 y 1109 de Italica y 2105 de Urgavo, actual Arjona (Jaén). Dos de ellas se hallan teñidos de culto imperial ${ }^{2}$ en la dedicación al dios - LIBERO PATRI AUG-y son testimonios únicos en la Península ${ }^{3}$. La de Urgavo parece la base de un gran pedestal o ara y las dos de itálica son a ciencia cierta aras ${ }^{4}$ y el tamaño de una de ellas $-1,65 \mathrm{~m}$ alto - hace presumible su adscripción a un templo de Liber en Itálica, pues en un reciente artículo de Alicia Canto sobre el mosaico del Circo y las Musas ${ }^{5}$ se establece una relación con el de Piazza Armerina en Roma, donde se aprecian tres pequeños templos a Liber, Libera y Ceres en la cabecera del Circo. Y puesto que en Italia también hay un culto a Ceres (Canto Epigr. It., 9), podemos conjeturar esta posibilidad.

Las "fórmulas de dedicación» son SACRUM en las tres, acompañadas en las dos primeras por otros datos como IN/OB HONORE y los D.S. P. D.D., D.D. y la circunstancia de que la ofrenda se haya celebrado con la concesión de unas representaciones teatrales - LUDIS SCAENICIS--, todo lo cual no es frecuente en los epígrafes del resto de Hispania. La "condición social» de los dedicantes es de ciudadanos romanos, a excepción del séviro de Itálica, que es liberto; precisamente la causa de dedicación de la estatua a Liber es el honor de haber alcanzado el sevirato: OB HONORE? (v.2). Ello podría tener alguna relación por la asociación entre la libertad y Diónysos-Baco desde época griega, por el apelativo de "Eléutheros".

Como poco habitual en las inscripciones que vamos a ver a continuación señalamos la aparición de un cargo importante en cada uno de los personajes que dedican, incluso varios como en la número 1.

En cuanto a la "época» parecen coincidir en el siglo ॥ d. C. y las de Italica más concretamente en el principio del siglo.

\footnotetext{
2 Para cuestiones sobre los dioses augustos en Hispania, y sus sincretismos, véase Etienne, R., Le Culte, págs. 302 ss.

3 HoYo CALLEJA, J. del, La importancia, págs. 222-223.

${ }^{4}$ Véase Canto, A., Epigr. Ital, 2 y 3.

5 "Némesis y la localización del Circo de Itálica", BSSA LIl (1986), pág. 69.
} 
Ante todo esto no podemos por menos que sorprendernos de la escasez de testimonios y de la peculiaridad de los mismos, sobre todo el haber aparecido dos de ellos en una capital importante - hecho inhabitual-, el presentar los dos únicos testimonios de culto a Liber Augusto en Hispania y el ser piezas de una extraordinaria calidad de material, conservación, tamaño e información. Lo cual puede indicar que el culto, oficial a todas luces, venía dado por personajes relevantes e influyentes en el municipio, y con cargos sacerdotales. Todo ello nos lleva a pensar en un culto superficial y en un sentimiento religioso poco vivo, rígido e inercial; nótese la ausencia en los tres de VOTUM, que aparece en otro personaje con cargo, en Monsanto, región vecina a la Bética y en casi todos los epigrafes de personajes sin cargo en Montaña Frontera. A esta conclusión llega también Vázquez-Hoys ${ }^{6}$.

"¿Es que no hubo culto a esta divinidad en la Bética, cuando es precisamente su figura la más popular y mayor número de veces representada en los mosaicos béticos? Tal vez la explicación de este hecho se encuentre en que Liber-Baco era precisamente popular entre las clases elevadas y mejor favorecidas por la fortuna, que le hizo representar abundantemente en los mosaicos y en estatuas para sus jardines, pero no le rindió un verdadero culto expresado en dedicaciones, templos y ofrendas que hayan llegado hasta nuestros dias en esta provincia".

El epíteto de AUGUSTO bien puede considerarse como un homenaje a Adriano por parte de los conciudadanos de su ciudad natal, siendo, según parece de una factura dentro del siglo II. De ahí su carácter urbano y fastuoso, lo que hace suponer un carácter municipal de este culto para Italica.

TARRACONENSIS

Desde los hallazgos en Montaña Frontera (Sagunto), se deben estudiar a mi juicio por separado éstas de las del resto de la Provincia Tarraconensis.

${ }^{6}$ "Algunas consideraciones", pág. 42. 
Dejando a un lado las de Montaña Frontera, se reducen a diez las demás: dos en el término de Sagunto, tres en el Conventus AsturumAsturica, León y S. Pedro de Montes (Orense), tres en el Cartaginiensis - Cartagena, Castellar de Santisteban y Castulo (Jaén)- una en Tricio (La Rioja) - Cluniensis - y otra en Donón (Pontevedra), del Lucensis.

Comenzando por los puntos más alejados, ya mostramos nuestro escepticismo sobre la atribución báquica de las aras graníticas de Donón y de la de Tricio. En cambio las tres de AS, tardias, no aportan datos de interés. La de Asturica, fechada en el $305 \mathrm{~d}$. C. ofrece un ejemplo de dedicación múltiple: Júpiter $\left(I^{*} \mathrm{O}^{*} \mathrm{M}\right)$, Mitra (SOLI INVICTO), Liber (LIBERO PATRI) y el Genio del Pretorio (GENIO PRAET (ORIANUS) o (-II).

Esta última, como la primera, se explica fácilmente atendiendo a la alta condición militar del dedicante: un itálico - IURIDEX PER FLAMINIAM ET UMBRIAM ET PICENUM- LEGATUS AUG (USTI) para las regiones de Asturiae y Gallaecia y DUX de la LEGIO VII Gemina. Pero lo más sugerente es la relación entre los dioses Mitra y Diónysos, unidos aqui bajo su aspecto benefactor, a juzgar por la fórmula dedicatoria PRO SALUTE SUA ET SUORUM. No es extraña esta vinculación en esta época tardorromana marcada por lo mistérico, que ya habia sido suficientemente señalada por algunos autores como Macrobio ${ }^{7}$ o el mismo Proclo, maestro de la escuela neoplatónica de Atenas ${ }^{8}$. Fuera de Hispania se detecta también este fenómeno, encontrándose en Gabies (Gallia) a VERUS, un SACERDOS LIBERI PATRIS ET SOLIS INVICTI ${ }^{9}$ y en CIL III 1548 y 1549 una nueva lectura ${ }^{10}$ ha sacado a la luz nuevos testimonios de la conjunción de cultos entre LIBER PATER y SOL INVICTUS MITHRA. En efecto, parece verosimil lo de Pastor Muñoz (Reflexiones, pág. 273)

"Fortuna, Hércules, Juno, Liber Pater, Minerva y Salus solo reciben culto en Asturica y por individuos venidos de fuera del territorio astur».

Por lo que se refiere a las inscripciones de Legio VII y S. Pedro de Montes, cabe destacar el epíteto CONSERVATORI aplicado a Liber en la de León, que en otras latitudes "convient fort aux "DII PATRES", donc

Saturnales | 18 (1-7) donde se identifican.

${ }^{8}$ Hymn, I, 40 y III, 28 asocia al Hijo de Semele con la divinidad solar.

${ }^{\circ}$ Cumont, Les Réligions, pág. 309, núm. 150.

${ }^{10}$ AE 1983, 799. 
ils sont les plus aptes à apporter leur garantie et leur concours dans les grands moments de la vie» "Nos atreveríamos incluso a extender ese patronazgo incluso a la vida vegetal de la vid. Por lo demás no podemos comentar más sobre dedicante ni otras fórmulas.

En una zona colindante a la Bética nos aparecen las inscripciones de Castulo y su vecina Castillar de Santisteban. Ambas arulas con SACRUM y LIBERO PATRI dedicadas por una mujer en Castillar y presumiblemente por un tal C. CRESCENTIUS en Castulo ${ }^{12}$. Parecen testimoniar, al contrario que en Bética, un culto más particular a modo de exvoto dedicatorio. Y por último en Carthago Nova una inscripción sospechosa, pero que sin embargo nos ofrece la dedicación única en Hispania de una pareja de ORGIOPATHAE ${ }^{13}$ o sacerdotes de Baco. Son un padre, liberto al parecer por su onomástica TITUS FLAVIUS EGLELIANUS, y su hijo CLYMPIANUS.

$Y$ antes de pasar a analizar los epígrafes de Montaña Frontera, no pueden quedar sin comentar sus dos vecinos del término municipal de Sagunto, desaparecidos en la actualidad, por cierto. Llama nuestra atención el soporte de la de Trull de utilización dudosa en paralelismo con otra dedicada a I. O. M., también ansata, recogiendo solamente el nombre LIBERO. La de Quart en cambio utiliza la fórmula compuesta LIBERO PATRI, sin más datos. De pensar en una influencia, sería más lógico considerar éstas como irradiaciones emanadas del culto del Santuario de la Montaña Frontera, hecho por devotos del dios afincados a escasa distancia del mismo.

Y por último nos introducimos en el Corpus de epígrafes hallados en la Montaña Frontera de Sagunto, verdadero filón quizás sin explotar ${ }^{14}, y$ que constituye todo un centro de religiosidad báquica, con problemas de sincretismo que aumentan su interés. Deben tratarse por tanto aquí tres problemas:

- la adscripción de los epígrafes

- la existencia de un Santuario a Liber, único conocido en Hispania.

- y un posible suplantación de divinidad ibérica.

1 Christol, M., "Un écho", pág. 132.

12 Opinión de PASTOR, M., "La religión romana", pág. 341, núm. 13, no aceptada por Hoyo Calleja, J. del, "Liber Pater".

13 Beltran, A., "Las lápidas", pág. 263, núm. 6. Para ver esta denominación fuera de Hispania, Orelli 1483.

${ }_{14} \mathrm{Si}$ bien el Dr. José Corell le ha venido dedicando sus estudios en ARSE 20, págs. 25-30, y sobre todo en su comunicación "El culto a Liber Pater" al Colloqui d'Epigrafia de Oct. del 88 (Cf.), del que, por su amabilidad en permitirme consultar el material, se extraen muchos datos para estas reflexiones. 
Uno: el número de los epígrafes publicados de los aparecidos en esta área asciende a 19, lo que supondría no sólo la concentración más grande de epígrafes báquicos en la península, sino también más de la mitad del total de 36 considerados por mí, como apunta Corell ${ }^{15}$. Esto, atendiendo a las consideraciones que expongo a continuación, no queda sino reducido a una tercera parte, admitidas 13 de esas 19 , lo cual no resta ninguna importancia al yacimiento saguntino, pero son amplificaciones ni comparaciones innecesarias.

En efecto, el estado pésimo de conservación de la mayor parte de las inscripciones, hechas por incisión superificial sobre caliza local, unido a su carácter rústico, hacen que solo en tres ocasiones pueda leerse LIBERO PATRI (Nos. 14, 17 y 25) y en dos $(16,24)$ LIBERO, con las consiguientes reposiciones. En otras sólo se lee LI[...] (15) o L[...] (23 y 26). De lo que se desprende que solo en estas siete podemos estar en la certeza de su dedicación al dios. Las otras seis muestran o bien una fórmula V.S.L.M./ S.A.L.M. (19-20-21-22-23) o un E[X VOTO] muy dudoso. Estas últimas han sido admitidas, como se dijo en su lugar ${ }^{16}$, por poseer VOTUM o fórmula religiosa equivalente, pues es lo más lógico, aunque no determinante, que la promesa se dirija al dios que consagra el lugar de culto.

Sin embargo, fuera de nuestro suelo, en Dacia, en el Templo de Liber de Sarmizegutsa aparecieron también inscripiciones dentro del recinto, indicándose en algunas sólo un nombre ${ }^{17}$ y han sido adscritas en su totalidad a Liber ${ }^{18}$. La diferencia a mi parecer es que todas ellas eran aras y en la Montaña Frontera el estado de las lascas no permite afirmar lo mismo.

Por este motivo caen fuera de este criterio lo que considero como mudos y devaluados restos de inscripición, que son los que corresponden a estos números de «El culto» de Corell:
4: CILIUS
6: VAL(...) (..)VER(..)
10: IUCUNDUS

15 «El culto», en Conclusiones: “Esto significa que una zona relativamente pequeña e ignorada a la hora de hablar del culto a Liber cuenta con más inscripciones que todo el resto de Hispania".

${ }^{16}$ Nota a 1.25 .

17 V.gr. $A E$ (1976), 564 con C(aius) Sped(ius).

${ }^{18}$ Acta Musei Napocnesis XII (1975), pp. 159-163. Véase com. de Horo CalleJA, J., del, "Liber Pater" a estas inscripciones. 
En los que aparece solamente el nombre incompleto del dedicante y

\section{4: CN I \\ 15: AN VIT \\ 16: $M$}

en que la presencia de ciertas letras de dudosa lectura no puede llevar a ninguna conclusión admisible y menos a incorporar estos fragmentos al conjunto de dedicaciones a Liber.

En definitiva, diremos que los epígrafes de la Montaña Frontera pueden dividirse en algunos de más calidad como las aras y pedestales mejor labrados y con letras capitales de mayor o menor uniformidad, como los siete de 14 a 20 , y en fragmentos de aras y placas con incisión y lectura defectuosa e incompleta, como los seis de 21 a 26, en los cuales no aparecería por lo general ni el nombre del dedicante, sino una mera estructura LIBERO VSLM.

El soporte tiene por materia la "Pedra de Sagunt» de caliza azulada en la mayor parte de los casos. Dada la gran diferencia con la piedra de la propia Montaña Frontera, clara y frágil, no parece verosímil el autoabastecimiento de piedra con la localización de un taller epigráfico anejo al Santuario ${ }^{19}$. Más bien hay que pensar en el remonte de los soportes hasta la cima, lo cual viene apoyado por su pequeño tamaño. No obstante se han hecho dos pequeñas placas en mármol blanco: 24 y 25 . En cuanto a la forma, además de estas placas de mármol, hay otra de caliza (23). Las marmóreas, de los ss. 1-11 y en las que aparece el nombre del dios indicarian dedicaciones a Liber por parte de personas más pudientes y la de caliza, la más tardía de la $\mathrm{M}$. Frontera - siglo III $\mathrm{dC}$ - no indica ni VOTUM ni nombre del dios.

Hay asimismo pedestales como los de 14, 16 y 19, que seguramente portaron una estatua, según se puede apreciar por los orificios de fijación que presentan 16 y 19; de 14 no lo sabemos por haber desaparecido. Su pequeño tamaño nos indica una estatuilla del dios de reducidas dimensiones.

Y por último siete árulas, indicio posiblemente más veraz de una ofrenda dirigida directamente en honor del dios. Para algunos estudiosos lo que nos encontramos son cuatro aras -18,20,22, y 26- y tres árulas $-15,17,21-$, lo que procede a nuestro juicio de un uso indiscri-

19 Beltran. P., «Hallazgos en Sagunto», pág. 247. 
minado de los términos, pues aunque no se establezca un canon dimensional para ara o árula, lo cierto es que excepto la 17, que es la de mayor tamaño y considerada arula las demás oscilan por igual entre los $26 \mathrm{~cm}$ de alto y 24 de ancho como promedio. Más variedad de tipos hay en cuanto a la profundidad, siendo algunas muy planas $-5 \mathrm{~cm}$ de $22-$ y otras más que altas y anchas, como 21. Las dos mujeres dedicantes to hacen en ara.

En su datación domina el siglo I, pero sin faltar el II (18) ni el III (22). Tampoco son uniformes las fórmulas de divinidad, ni las dedicatorias, predominando el V.S.L.M.

Un segundo planteamiento se refería a la existencia de un santuario a Liber en la cima de esa elevación $(378 \mathrm{~m})$ de difícil acceso. No ya sólo los primeros exploradores de la zona, como J. B. Figols y V. Daniel en 1818, B. Ribelles, que transmite los descubrimientos de los anteriores, en $1820^{20}$ y $\mathrm{P}$. Beltrán en $1951^{21}$, sino el propio Corell ${ }^{22}$ afirma que en la actualidad puede apreciarse la planta de un aediculum, consagrado a Baco por las inscripciones alli halladas. También se ha especulado con que la inscripción 14 pudiera ser conmemorativa de la construcción o restauración del templo de Liber a expensas del Municipium Saguntinum, lo que indicaría un cierto arraigo de este culto en la localidad. Todo ello cuenta con el inconveniente de que las excavaciones se han llevado a cabo desde un comienzo de modo muy asistemático, hasta el punto de afirmar Corell ${ }^{23}$ que «En la Montaña Frontera se han removido todas las piedras, pero no se han hecho nunca excavaciones". Todo ello nos impide hoy ver algo en esas ruinas informes.

$\mathrm{Y}$, saliendo al paso de la tercera cuestión, esto nos lleva a considerar que ese lugar debía ser desde antiguo un centro cultual no solo por su disposición natural de elevación sobre una fértil llanura, sino por los hallazgos que en lengua ibera, datados en el siglo III a.C., han aparecido junto al aediculum. Los romanos oscilan entre el siglo I y el III d.C. No parece, pues, posible una convivencia de cultos, sino más bien una suplantación, que viene propiciada por el conocimiento del nombre de la divinidad ibérica ${ }^{24}$ : Ildubocon.

20 "Restos de un templo", págs. 253-256.

21 "Hallazgos en Sagunto", pág. 246.

22 "El Culto", Conclusiones.

23 "El Culto" Conclusiones.

${ }^{24}$ Para el conocimiento de las inscripciones ibéricas con el nombre lldubocon, véase Oliver Foix, A., "Grafitos"; Silgo GAUCHE, L., "¿lldutacon...?; Fletcher-Silgo "Repertorio". 
Primeramente se leyó mal como lldutacon ${ }^{25}$, pero el mismo Silgo en un reciente artículo ${ }^{26}$ corrige la lectura en -bocon, acercándolo a una etimologia de antiguas raices incluso vascas ("oko" = "racimo de cualquier fruto y en especial uva») y aquitanas («Bocco" dios local del Alto Garona), ambos encerrando una idea de fertilidad y abundancia. Lo cual lleva a Silgo a no dudar de "su asimilación al Liber Pater de las inscripciones latinas" ${ }^{27}$.

Entre los dedicantes aparecen dos mujeres: [H]ERENNIA (18) y [BA]EBIA CN. L. [GR]AECA(20). Esta escasez es frecuente en las inscripciones a Liber, que en Hispania sólo ofrece otros dos testimonios: Castellar de Santisteban -VA-[LERIA] PROBA ${ }^{28}$ (9) y Trujillo (27): PONCEIA BOUTI $F$. Tanto éstas como la de la inscripción número 18, de $M$. Frontera son libres, como el resto de los dedicantes masculinos del lugar, figurando Baebia Graeca como liberta. Esto puede verse apoyado por el estudio de la onomástica, con la estructura trinominal para los hombres. Los nomina son los habituales entre las inscripciones de Sangunto, a excepción de [H]ERENNIA, que ha recibido, no obstante otras interpretaciones ${ }^{29}$. Los cognomina son latinos a excepción del de 16, AXSIOCUS, que parece griego. En resumen, los datos corresponden a unas personas de clases altas, sin rastro de indigenismo.

LUSITANIA.

Las diez inscripciones que pertenecen a estos "Conventus" aportan nuevos aspectos inéditos sobre la figura de Liber en Hispania.

En primer lugar es de notar la localización de seis de ellos. Sin formar una unidad como los de Montaña Frontera, sí puede detectarse una influencia dada la gran proximidad de los puntos en que han aparecido. Se concentran en torno a la población de TURGALIUM las inscripciones de Robledillo de Trujillo, Aldehuela de Mordazo y Heguijuela, y en

25 Véase nota anterior.

26 "La antroponimia"Bocon, pág. 70.

27 Idem.

28 Hoyo Calleja, J. del, La importancia, pág. 278.

29 Beltrán Lloris, F., ELST, 172: HE|RENNIUS---) y Alföldy “Ein Corpus", pág. 172: LIBIERIUS---]. 
sus cercanías la de Zorita. Desplazada hacia el $\mathrm{N}$ tenemos la de CAURIUM.

Esta contigüidad viene a determinar determinados rasgos comunes en el culto de los lugareños a la divinidad al tiempo que grandes originales.

Primeramente nos encontramos con la aparición de la pareja LiberLibera, de la que sólo poseíamos noticias literarias ${ }^{30}$, no referidas directamente a Hispania, donde su presencia iconográfica es nula. Su fórmula dedicatoria es LIBERO LIBERAE en Aldehuela y Robledillo y LIBERAE LIBERO en Zorita. En el de Aldehuela de Mordazo puede apreciarse la peculiaridad de que tanto el campo epigráfico como la pileta de ofrendas se hallan perfectamente divididos en dos, como si se tratara de dos aras dedicadas cada una a un dios que han sido unidas. Al tiempo tenemos que considerar la dedicación a LIBERAE que figura en el ara de Herguijuela, junto a la de Herdade, más al Sur. Esto es algo que, insólito en el resto de Hispania, no deja de ser escaso en otras Provincias ${ }^{31}$ también. De hecho la asombrosa anteposición a Liber en Zorita nos puede acercar a la importancia de esta diosa que toma el nombre de su pareja masculina.

Las fórmulas dedicatorias, unidas a la materia local en que se han esculpido las aras - forma en sí religiosa-, denotan una cierta sinceridad, por así decir, de la devoción, hecha en todos los casos a título personal por hombres y por una mujer en Trujillo. Estas fórmulas son directamente religiosas como L.A.V.S. (TURGALIUM), A.L.F. (CAURIUM), V.S. (Zorita) e incluso con expresiones de sumisión al dios como EX VISU (Aldehuela y CAURIUM) y EX VOTO en la de Libera hallada en Herguijuela. El hecho de hacerlas a la pareja de divinidades pudiera hacernos pensar, a la vista de su significado mitológico, en un culto que celebra e invoca para si $^{32}$ y los campos la fertilidad. No hay que olvidar que en otras provincias han aparecido algunas inscripciones dedicadas a LIBERO PATRI ET LIBERAE MATRI ${ }^{33}$.

Las dos inscripciones de TURGALIUM y CAURIUM, núcleos más romanizados que estas otras aldeas, pudieran ser reflejo de un dedicante

\footnotetext{
${ }^{30}$ Véase para todo este tema del culto a Liber-Libera el capitulo inicial de GarCia SANZ, Baco en Hispania.

${ }^{31}$ DE Ruggiero, Dizionario Epigraphico IV, págs. 834-835, sv.

32 Incluso Rosco-Télez "Liber-Libera", pág. 142 arriesgan la teoría de que el ara bipartita de Aldehuela pudiera haber tenido la intencionalidad de propiciar la feracidad de una pareja.

${ }^{33}$ CIL III, 12572. Dacia.
} 
emigrado ${ }^{34}$ de otra región, ya que son las únicas en presentar, situadas en zonas urbanas, la fórmula LIBERO PATRI común para el dios en el resto de la península, pudiendo revelar una actividad no-agrícola en sus dedicantes, sin que pueda darse a esto más importancia que la de una conjetura razonada.

Respecto a los cuatro epigrafes lusitanos, pudiera observarse también esa doble corriente de culto más urbano y romanizado al dios en solitario o en relación a su paredra Libera, más vinculado a ideas de fecundidad, propias de lugares rurales. Así, mientras en OLISIPO y CONIMBRIGA se venera a LIBERO PATRI sobre calcárea rosada, en Monsanto se une Libera - a un LIBERO PATRI y no sólo LIBERO- y en Herdade aparece la diosa en solitario, siendo un epígrafe carente de otro elemento sino de este nombre, ambos grabados en granito local.

Dentro del capítulo de peculiaridades únicas que hemos visto en este ámbito local de la Lusitania (ara bipartita, granito, fórmulas ex visu/voto, posición LIBERAE-LIBERO), se añade ahora este hapax de la dedicación a PATRI LIBERO que aparece en OLISIPO, con una fuerte dedicación de SACRUM, reforzada por el V.A.L.S., desconocida en los epígrafes a Liber en Hispania, como el A.L.P. de CONIMBRIGA, propio al parecer ${ }^{35}$ de la región lusitana.

La desconexión entre estos cuatro epígrafes, juzgando exclusivamente con criterios de distancia, parece completa, acercándose más también por tipo de culto el de Herdade al núcleo turgalense.

La factura de epigrafes sobre el pobre granito local, además de la sensación de indigenismo que nos produce, según dijimos antes, se escapa frente a los dos epígrafes en calcárea a una adscripción a categorías de dedicantes, pues mientras VALERIUS DAPHINUS (CONIMBRIGA), importante personaje hispano-romano, dedica en calcárea, el «veteranus" L. MARCIUS MATERNUS de Monsanto lo hace en granito. Ambos poseen dedicatorias en otros lugares, especialmente VALERIUS,

${ }^{34}$ V. ARIAS, I., “Materiales epigráficos para el estudio de los desplazamientos y viajes de los españoles en la España romana", CHE XII (1949), págs. 5-50 y "Desplazamientos y contactos de los españoles en la España romana", Id., XXI-XXII (1954), págs. 67-98.

Para la emigración femenina (vease PONCEIA de Trujillo), DEL HOYO, J., La importancia, págs. 403-418

${ }_{35}$ Etienne, R. y Otros, Fouilles de Conimbriga. II, pág. 34 y núm. 112. 
que aparece en EMERITA ${ }^{36}$, mientras MARCIUS ha dedicado en un lugar muy próximo, la actual Ildanha-a-Velha ${ }^{37}$.

\section{CONCLUSIONES: EL LIBER PATER EPIGRÁFICO ${ }^{38}$ DE HISPANIA}

Ya una visión de la epigrafía báquica en el Imperio nos llevaba a considerar los distintos carices que tomó en cada región este culto, mezcla tal vez del indigenismo latino de Liber y el de la región en cuestión, tocantes en lo fundamental y variantes en las formas y expresiones junto a la entidad "culta" del Diónysos griego romanizado y adscrito a la Religión oficial y a veces al Culto Imperial. Así, además de todas las inscripciones que aparecen en $C / L$ por todo el Imperio, son de más reciente hallazgo las de Petra, en Arabia ( $A E$ 1968, 519). Las de Pannonia, Mesia y Dacia, que a juzgar por hallazgos recientes tuvieron un culto especial a la pareja Liber-Libera, al parecer ser el trasunto de dos divinidades arcaicas con un culto de ultratumba ${ }^{39}$. $Y$ las de África: yacimiento de Leptis Minus (AE 1968, 630) y templo de Qçour el-Melek, en Uzappa (AE 1969-70, 646). Al parecer en esta parte del Norte de África se operaron sincretismos entre la población de paso como latinos, griegos, semitas y bereberes ${ }^{40}$.

Por lo que se refiere a Hispania y a la luz de lo visto, se desprende lo siguiente:

1. "Topográficamente» * los epígrafes se agrupan en zonas: muy puntuales como la de Sagunto-Montaña Frontera -13-, o en orden de cercania como los núcleos de TURGALIUM -6-, ASTURICA -3-o CASTULO -3-, quedando verdaderamente aisladas, al menos por hoy, las de Tricio, las cuatro del actual Portugal, la de ITALICA y la de CARTHAGO NOVA.

También la Epigrafía parece orientarnos hacia un culto a Baco en Hispania dentro del ámbito de privado, siendo escasísimos los testimo-

${ }^{36}$ BRAH XXV (1894), pág. 465.

37 Almeida, F. de, Egitania.

${ }^{38}$ Término que escuché al Dr. J. del Hoyo en su comunicación al Col. "Archeologie de la vigne et du vin" (Paris 1988). Véase Horo CalleJA, J. del, "Liber Pater".

${ }^{39}$ Perdrizet Cultes et Mythes du Pangée, pág. 96 citando especialmente CIL III 686.

${ }^{40} L P$, pág. 235.

* Véase mapa al final de trabajo. 
nios de un culto oficial e incluso imperial. Como dijimos al comienzo, los núcleos no resultan ser grandes ciudades, sino en la mayor parte pequeños enclaves de población, si bien no faltan algunos dedicantes que podian residir en ciudades, no destacadas en general en el culto a Baco, según los testimonios. De igual modo los dedicantes no parecen, según lo visto antes, grandes personajes de la vida imperial o municipal, sino en su mayor parte ciudadanos libres del tercer ordo, libertos o mujeres.

Todo lo cual nos lleva a un intento de explicación de la ausencia de epígrafes báquicos en ciudades tan romanizadas como TARRACO o EMERITA en las que sí hay representaciones dionisiacas. Sin poder afirmar que nunca existieron unos testimonios -ahí están ITALICA o URGAVO para ser excepción de la aventurada norma- que pueden permanecer ocultos o haber desaparecido en cualquier época, sí creemos que esa escasa presencia de Baco y de todas las divinidades romanas en la religión oficial es un paso para entender la ausencia del dios de estos importantes núcleos de la romanización. Ahora bien, ante la gran proliferación de objetos de culto o de meras representaciones iconográficas dentro de lo privado en estos mismo lugares, parece que nos acercamos a dos modelos de religiosidad que poseen sus propios modos de expresión: la artística y la más propiamente religiosa, alejada ésta del afán decorativo al menos en todos los testimonios hispánicos. La primera nos revela más que un culto, la representación iconográfica de unos valores expresados en la mitología báquica: la abundancia, fecundidad y bienestar, que parecen responder a los gustos de una clase social acomodada.

La expresión no artística, decíamos, del epígrafe obedece en primer lugar a un "acto" de dedicación al dios, sin una finalidad lucrativa para sí, hasta el punto que el objeto, sea ara, placa o pedestal, no se halla en la propia casa sino en un templo o recinto sacro. También la finalidad es claramente votiva según la fórmula correspondiente, según hemos visto. En los epígrafes aparecen personas de toda condición social, incluso muy pobres que sólo pueden ofrecer una lasca rayada. En todo caso no hay por qué pensar en una mayor "devoción" en este caso que en el primero. Se trata de expresiones diferentes sin más, siendo esta tradición de los epígrafes, especialmente de las aras, parte de una tradición que remontaba a los antepasados y a los cultos antiguos, dignos de todo respeto y pervivencia para todo romano, aunque su postura hubiera evolucionado necesariamente hacia una religión más difusa y simbólica. No obstante también en los epigrafes pudo darse una falsa postura religiosa ${ }^{41}$ al convertir el ara y espe-

41 Hoyo Calleja, J. del, «Relación culto/estrato". Cuadro final, donde se puede apreciar 
cialmente el pedestal, por lo general de mármol blanco y con letras capitales, en motivo de ostentación, para admiración pública o con finalidad propagandística.

Así pues en las demarcaciones urbanas de TARRACO y EMERITA podemos decir que no ha sido representativa la presencia de epígrafes a Baco por poseer sus particulares afincados allí un sentimiento religioso diferente del de los habitantes de las poblaciones cercanas -TURGALIUM y sus cercanias; Montaña Frontera y alrededores- que se ha expresado de modo distinto al epigráfico. Para ellos Baco no era tanto un objeto de culto como una figura "emblemática" de admiración.

2. En cuanto a la «fórmula de dedicación» a la divinidad LIBERO/ LIBERO PATRI, con ausencia de BACCHUS o DIONYSUS en dativo, nos parece que puede suceder en parte lo que en otras divinidades griegas, con el nombre únicamente romano -v.gr. IOVI-, si bien en otras divinidades se de una dualidad -ASCLEPIO/AESCULAPIO- de sorprendente adscripción a dedicantes griegos-nombre romano y romanos-nombre griego. El hecho definitivo es que no existe en el mundo romano otra fórmula dedicatoria a este dios que la hallada también en nuestro suelo, quedando evidenciado a través de las fuentes literarias, como puede leerse en la citada obra de Bruhl en el capítulo correspondiente a los autores de siglo I dC, la multidenominación de la divinidad ${ }^{42}$.

Quizás el nombre de Liber haya sido mantenido por ser más ancestral a los romanos que el del extranjero Baco o Diónysos, si bien se reconocen e identifican con total igualdad. Por ese mismo carácter del pasado puede que no haya formado antropónimos tan fácilmente como DIONYSUS, habitual en todo el Imperio ${ }^{43}$. En Hispania no es muy frecuente ${ }^{44}$, si bien pudiera ser hasta cierto punto de notar el hallazgo en Montaña Frontera de un epígrafe con este cognomen ${ }^{45}$.

3. En las "fórmulas dedicatorias" como hemos visto predomina SACRUM, al que se añade un IN/OB HONOREM, D.D., D.S.P. D.D., FECIT. Por contraste con "fórmulas" de un Santuario como el de Montaña Fron-

a partir de datos intrínsecos y extrínsecos la comparación del sentimiento religioso de diversas clases sociales y su expresión en epigrafes de distinto tipo.

${ }^{42}$ Esta idea ha sido desarrollada entre las págs. 518-520 de GaRCIA SANZ, O., Baco en Hispania, refiriéndose a la triple nomenclatura Diónysos-Liber (Pater)-Bacchus.

${ }^{43}$ Solin, H., Die Griechischen, págs. 302-309, 1359 y 1372 , donde se recogen entre el periodo Sila-siglo Iv dC. 282 DIONYSIUS y 75 DIONYSIA, siendo el núm. 15 de frecuencia de nombres griegos en Roma.

${ }_{44}$ CIL II 2056, 2474, 2537, 2850, 4062 y 4157

${ }^{45}$ Roca Ribelles. F., “Lápidas inéditas", ARSE 20, pág. 62. 
tera, en que vemos casi siempre el V.S.L.M., podríamos pensar que ésta es una fórmula más propia de pedestales o aras que se van a colocar en un templo, quedando para el ámbito privado y doméstico otras fórmulas como SACRUM, L.A.V.S.(27), A.L.F.(31), A.L.P. (36), o bien que V.S.L.M. indica una mayor intencionalidad religiosa que SACRUM.

Frente a esto puede objetarse que no todos los que prescinden del VOTUM son poderosos personajes que dedican en mármol y con fórmulas abultadas. Tampoco sabemos si el mismo V.S.L.M. pudo caer en el desgaste, hasta perder su primitiva fuerza unitiva a la divinidad, recordando ese "re-ligare" que define la religión.

Tampoco falta quien, en apoyo de esto, acumula las dos fórmulas -35- pareciendo deducirse de aqui que para este personaje el mero SACRUM no alcanzaba a expresar su sentimiento religioso, expresado con estas fórmulas y en ara de calcárea, lo cual nos indica, aunque no aparezca, un rango social medio-bajo.

Pero al lado podemos fijarnos en que otros personajes que dedican en las mismas circunstancias se expresan con un mero A.L.P. (36) o un A.L.F. (31), que puede equivaler perfectamente a los dos S.A.L.M. de Montaña Frontera, uno sobre arula (22) y otro sobre placa (23), que resultan anómalos en un ámbito mayoritario de VOTUM.

Haciendo conjetura desde estos datos uniformes podríamos pensar que los dedicantes de estas dos piezas saguntinas pudieran ser personajes de más relevancia social y económica que el resto, si tenemos en cuenta que coinciden curiosamente la única dedicatoria sin VOTUM con la única dedicada por dos hombres públicos y por decreto decurional. Pero en el resto de la Península no podemos dejar de señalar otra coincidencia que parece contradecir ésta: la única dedicatoria, hecha por más en ara, en que se ha grabado el V.S.L.M. corresponde a un veterano.

4. Nos es desconocida tanto la "profesión" y "puesto" de la mayoría como su «condición social». En los casos de ASTURICA LEGIO VII y Monsanto puede apreciarse el carácter militar que en las provincias danubianas tenía este culto ${ }^{46}$, pues en ellas entró por medio de las legiones.

Por lo demás, en la mayoría muy probablemente nunca se indicó el cargo social, seguramente por ser irrelevante, perdiéndose en otros casos. La concentración de cargos se realiza en los tres epigrafes de la

${ }^{46}$ LP, pág. 216. 
Bética, y en el de Asturica, que muestran personajes en que se han acumulado varios servicios imperiales. De inferior categoría tenemos dos duóviros bajo una sola inscripción en Montaña Frontera, un séviro en Itálica y un Veteranus en Monsanto. Con cargo sacerdotal, dudoso en ambos casos, dedican un Augur en Itálica y dos Orgiofantes en Cartago Nova. Tanto en éstos como en los citados sin cargo expreso predominan los cives romani como muestran las onomásticas trinominales, a los que se añade algún liberto destacado en cargo seviral como el número 2 de Itálica o sin él como los dos de Montaña Frontera (Núms. 20 y 23), siendo el primero de ellos una liberta.

Todo ellos nos ayuda a pensar, considerando aparte el caso de la Montaña Frontera, que los personales más destacados, como ya comentamos al hablar de la Bética, muestran una menor autenticidad en su culto, que queda hecho medio de propaganda personal, con enumeración de cargos, incluso bajo alguna referencia religiosa (V. 1. IN HONORE PONTIFICATUS) y sin VOTUM, a lo sumo con una coletilla formularia (PRO SALUTE del núm. 6) que no parece sino solicitar del dios la conservación en el bienestar, pues se hace sin SACRUM siquiera. Esta será la religiosidad que el resto de las fuentes arqueológicas subrayarán por lo general.

5. También una breve referencia al "soporte» de los epígrafes nos puede revelar algo sobre la condición del dedicante y su forma de dirigirse a Liber. Partimos de la consideración del ara como la forma clásica de objeto religioso para hacer una ofrenda a una divinidad. Su tamaño nos puede informar de un uso oficial o particular. Entre las veinte que estudiamos la 2 parece pertencer a ese culto oficial que en este caso requeriría la presencia de un templo, como dijimos antes. $Y$, por contra, las arulae de Montaña Frontera, la del culto personal en un Aediculum. Curiosamente todos los soportes de la Lusitania son aras, bajo rasgos y formas muy distintas en su texto. El pedestal, que sustenta una estatua, no tiene por qué carecer de ese sentido sacro, pudiendo interpretarse primitivamente como una ara en que se ofrenda no una libación o sacrificio cruento, sino una imagen del dios. En época romana, no obstante, parece tener más un carácter decorativo, con una referencia religiosa. Entre los siete que presentamos en ningún caso se ha hallado ningún resto de estatua, sólo los orificios de los clavi que la unían a la base. La mayor es la de Urgavo, que pudo sostener a una figura de tamaño natural, siendo los demás de un tamaño medio. Por último se han hallado también cuatro lápidas o placas dedicatorias, la mayor parte en la Montaña Frontera, con el nombre del dios en dos casos (24 y 25) y probable- 
mente sin fórmula dedicatoria. Pudieron hacer la función de un exvoto, como otra forma de presentar la dedicación en un recinto sagrado. Permanece en la conjetura el uso del "cilindro" del Trull des Moros. (Ver Figura del final del artículo).

El estudio de los «materiales" en que se han inscrito los textos epigráficos aportan algo sobre la calidad y la factura de la pieza. Dejando a un lado la dudosa lápida de Tricio, de alabastro, el material más noble es el mármol, que aparece en contadas ocasiones, con culto oficial a Liber Augusto (1 y 3) y por parte de personales con cargo público $(2$, y muy probablemente 6 y 7 ), si bien otros (14 y 34) han utilizado la piedra del lugar, evitando gastos mayores. El granito es usado exclusivamente en la zona de Turgalium y da un resultado pobre, aunque las letras tengan calidad, con un esfuerzo redoblado. Más fácil resulta el trabajo en calizas o calcáreas, pero su conservación suele ser penosísima, con exepciones, como la de Conimbriga que presenta una gran calidad en la letra y en la disposición del campo epigráfico, que, junto a la relevancia del personaje, hubiera merecido otro material.

Como resultado del análisis de las distintas partes de los textos se puede concluir que no puede hablarse sino de una tendencia a que coincidan personajes importantes con fórmula SACRUM, acumulación de otras referencias y cargos, escrita con letras de calidad sobre pedestal - no ara- de material costoso, como el mármol. La resultante religiosa, si puede hablarse así, puede ser de menor consistencia que la que hace un personaje sin cargos, que escuetamente indica su nombre y el del dios, entre los que sólo se expresa el lazo del VOTUM toscamente escrito sobre un ara de piedra del lugar, caliza o calcárea.

Por último diría que sin duda todos hemos echado de menos en cualquier punto de la península, algún testimonio que corroborase el patronazgo del dios sobre la vid y el vino, que por otra parte son contados en el Imperio ${ }^{47}$.

$Y$ si bien es verdad que

«la mayor o menor aceptación [de una divinidad en un medio] parece que está en relación directa con el hecho de que se haya producido una "interpretatio" romana de una divinidad indígena preexistente, en este caso relacionada con el vino o la vendimia" ${ }^{48}$

${ }^{47}$ CIL III 3294 Y 10275.

48 Canto, A., Epigr. Itál, pág. 128. 
no podemos dejar de pensar que en esta implantación de Baco en la Península, seguramente de época colonizadora, han tenido mucho que ver los sincretismos, que sólo en Montaña Frontera aparecen con cierta claridad. Incluso para una zona sin epigrafía dedicada a Liber, como la salmantina afirma Blázquez ${ }^{49}$ que "cuando se introdujo [el culto a Baco] lo hizo mediante el sincretismo, como en los casos de Júpiter".

\section{CUADROS-RESUMEN}

\section{Observaciones}

A continuación se ofrece primeramente el cuadro-resumen de las inscripciones de la Montaña Frontera (Sagunto). Como referencia se da el número correspondiente de Correl, J. «El culto". En los apartados de "Dedicante" y "Fórm[ula de la] divinidad" se ha restituido por completo el texto, cuando es presumible. El signo "\#» indica que el texto nunca figuró, mientras que «?» denota pérdida o lectura muy defectuosa. En el apartado de "Condición social» figuran estas claves:

L : libertus.

$S$ : servus.

CR: cives romanus.

De aquí parece desprenderse la idea de una divinidad popular, a la que se da un culto comunitario bajo un auspicio de fecundidad y protección, al modo de un auténtico patronazgo. Un culto por tanto arraigado en una población concreta. Un culto más primario que parece descubrir a un dios Liber agreste, más que al bello objeto de los artistas, si bien haya un sustrato común, más elaborado y "urbanizado" por una parte que por otra.

Presentamos ahora, diferenciando con una línea en blanco los Conventus, un cuadro-resumen de los epígrafes hispánicos, excluyendo los

${ }^{49}$ Religión y Sociedad, pág. 4. 


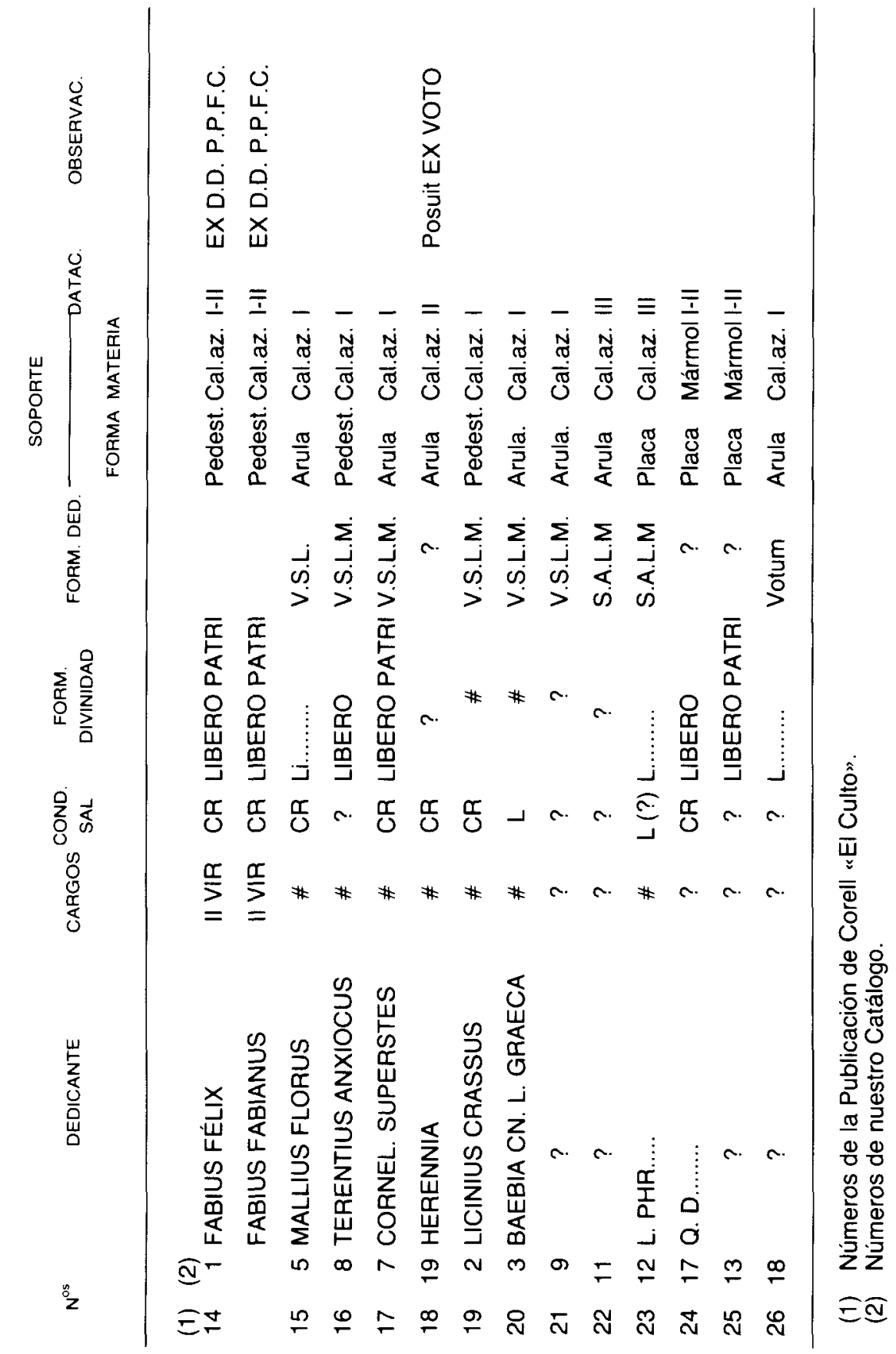


de Montaña Frontera, que aparecieron antes. V. las “Observaciones» al cuadro superior, teniendo en cuenta:

- que el número que aparece es el de nuestro inventario.

- las claves de SOPORTE

- Forma (F.)
A: ara
L: lápida

- Materia (M.)

A: alabastro

$\mathrm{Cz}$ : caliza

Cc: calcárea

G: granito

M: mármol

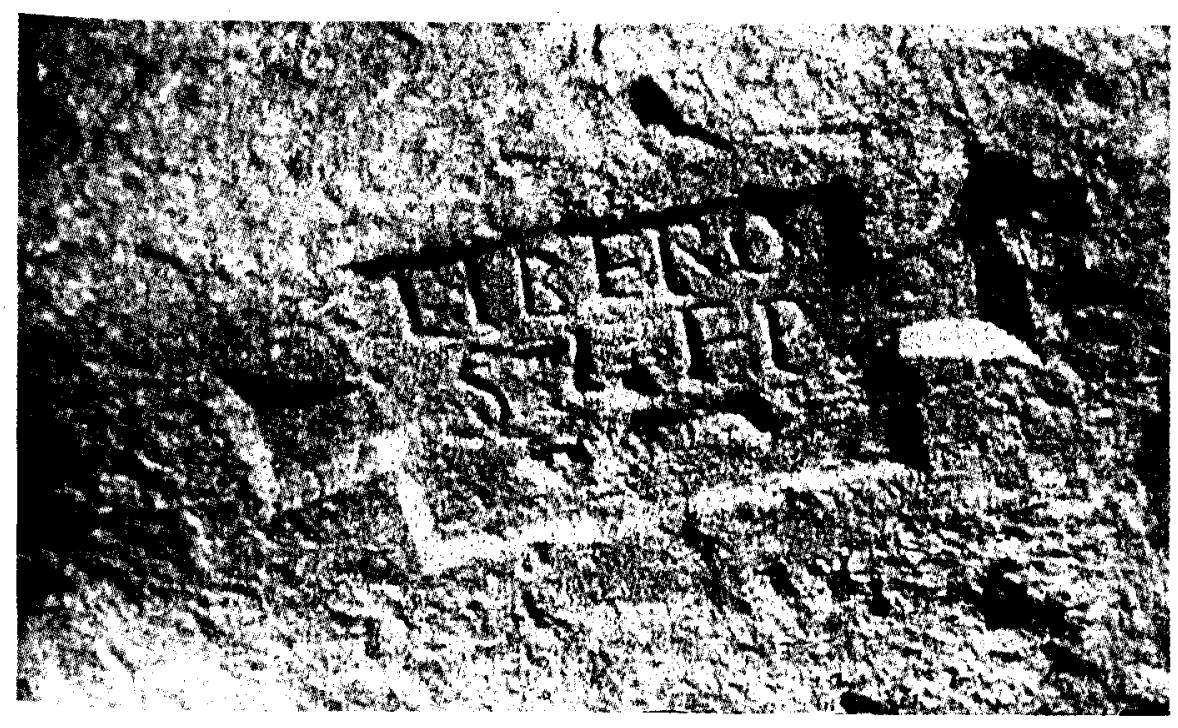

Inscripción a Liber en un cilindro de caliza. Trull, Sagunto (Valencia). 


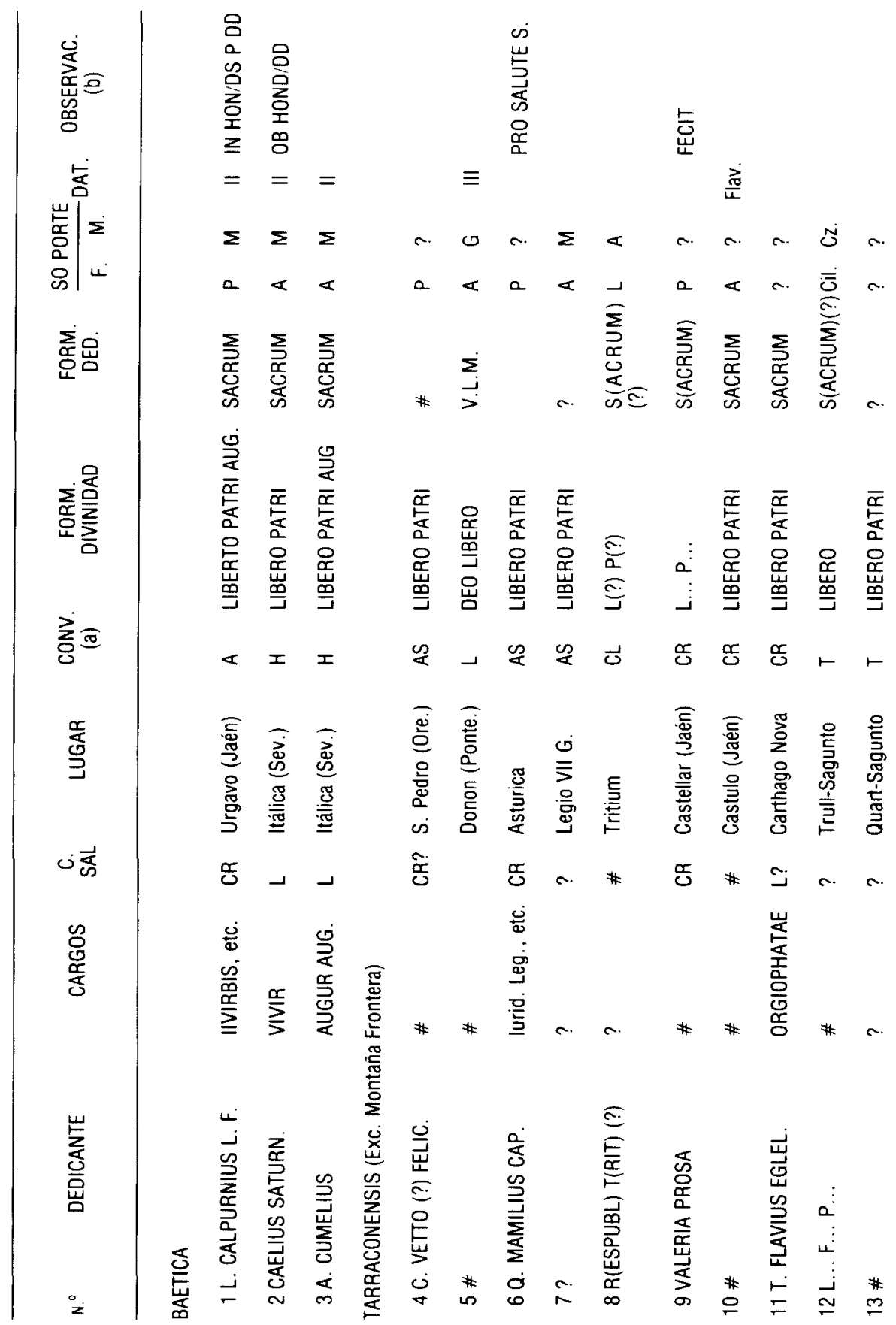




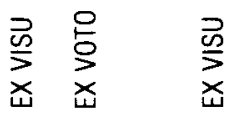

م 0000000000

$<<<<<<<<<$

晟

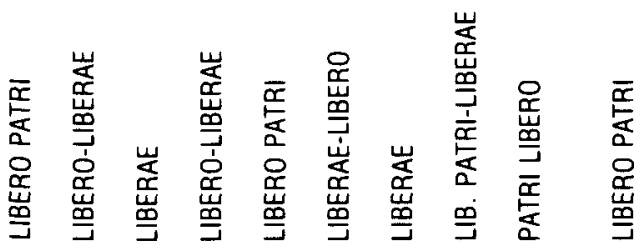

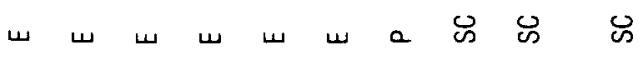

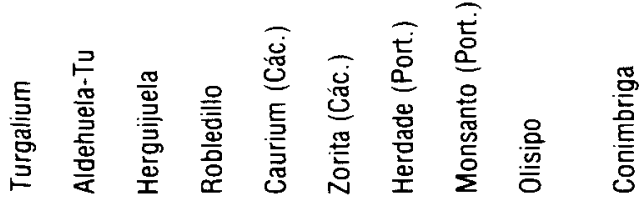

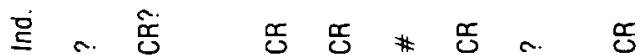

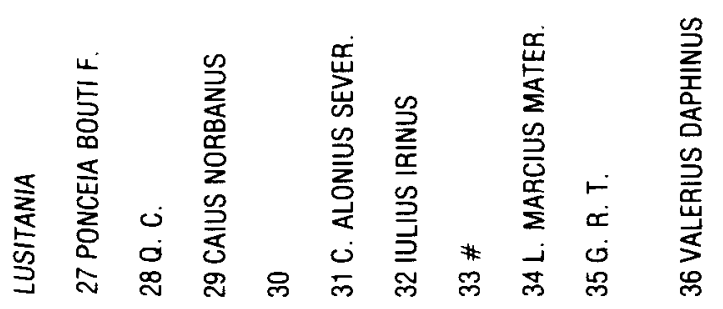

हิ

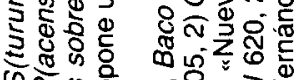

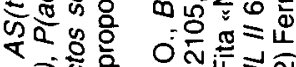

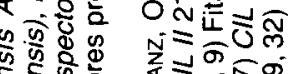

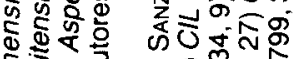

ڤᄂ

हैं क

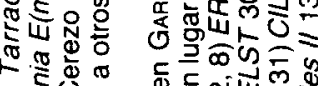

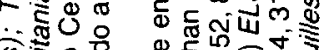

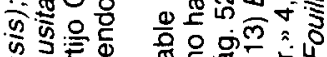

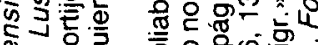

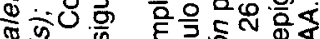

के का क्षे

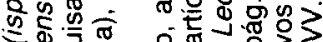

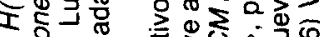

ข

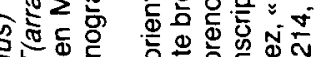



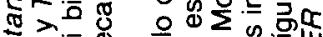

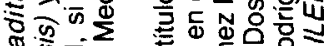

ช

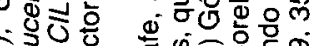



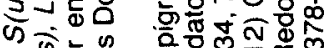

$>\frac{9}{\omega}$ क व

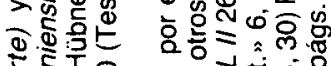

농

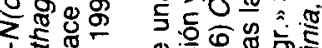

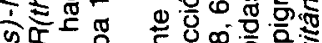

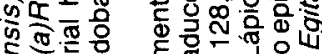

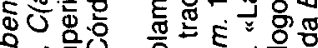

ริธ亠丷厂

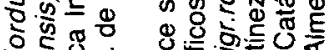

웡워

ริ는

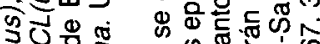

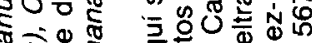

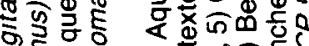

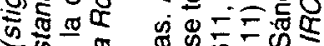

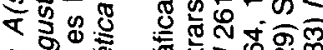

ชั क्ष

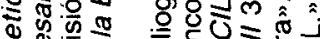

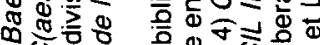

厅品

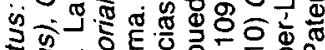

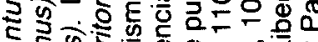

ब



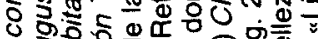

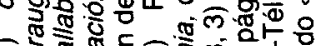

ख

एक 


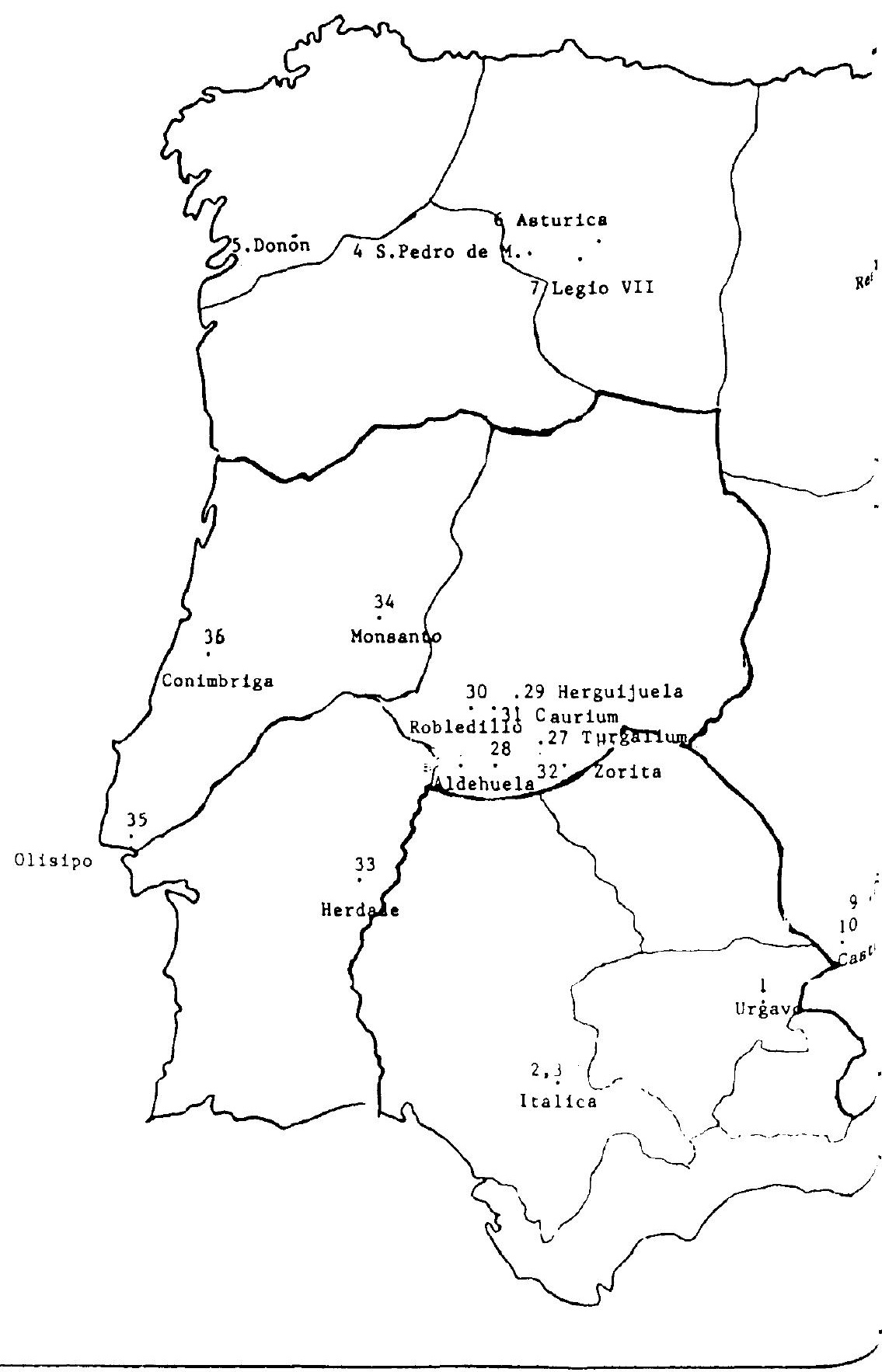




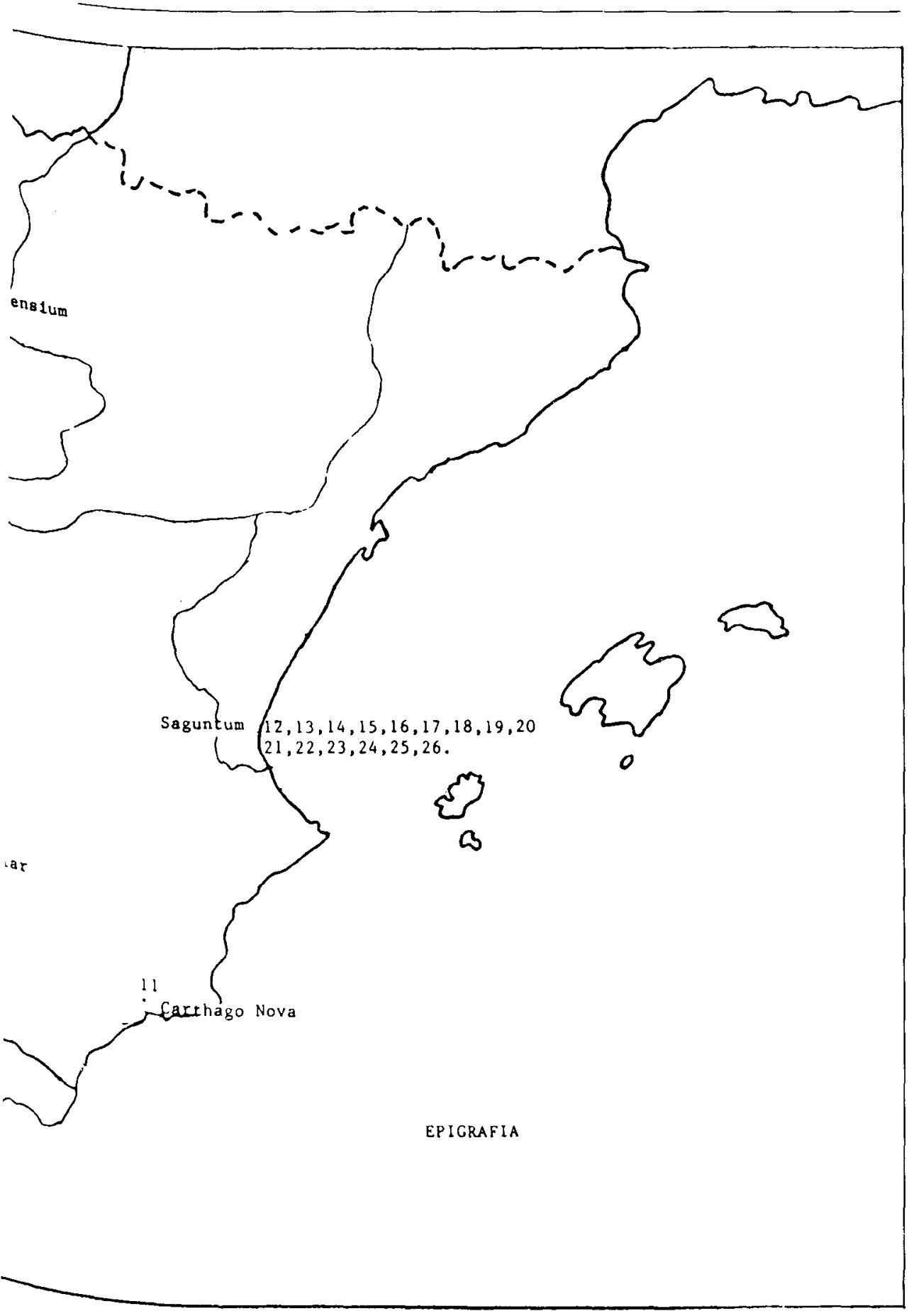




\section{BIBLIOGRAFIA}

Abreviaturas de libros, revistas y otras publicaciones.

AE : Anné Epigraphique. CNRS. Press. Univers. de France. Paris.

AEA : Archivo Español de Arqueología. CSIC. Madrid.

ARSE : Arse. Centro Arqueológico de Sagunto (Valencia).

BRAH : Boletín de la Real Academia de la Historia. Madrid.

CIL : Corpus Inscriptionum Latinarum. Ac. Litterarum. Berlín.

EAE : Excavaciones arqueológicas de España. M. ${ }^{\circ}$ Cultura. Madrid.

ELST : BELTRAN LLORIS, A., Epigrafía latina de Saguntum y su territorium Valencia.

ERR : EsPINOSA RUIz, U., Epigrafia romana de la Rioja. Logroño, 1986/ 1980.

ILER : VIVES, J., Inscripciones latinas de la España Rom. Barcelona, 1971-2.

IRCP : D'EnCARnaÇAO, J., Inscripçôes romanas do Conventus Pacensis. Coimbra, 1984.

LP : BRUHL, H., Liber pater Paris, BEFAR 175, De Boccard. 1953.

Bibliografía por autores.

ALFOLDY, G. : "Ein Corpues der Römischen Inscriften aus Saguntum and Umbebung", AEA 54 (1981), págs. 130-138.

AlmeIDA, F. de : Egitânia. Lisboa, U. de Lisboa, 1956.

Beltrán Martínez, A. : "Las lápidas latinas religiosas de Cartagena», AEA 23 (1950), págs. 263, 6. 
Beltran Villagrasa, P. : «Hallazgos en Sagunto», AEA 24 (1951), págs. 246-247.

BlázQuez MNEZ, J. M. : “Religión y sociedad en las inscripciones de Salamanca", Actas Col/loqui d'Epigrafía. Tarragona, octubre 1988. En prensa.

BouzA, F. y otros : «Las aras del santuario galaico-romano de Donón», Cuadernos de Estudios Gallegos XXVI, 78. CSIC. S. de Compostela 1971, págs. 64-81.

Canto De Gregorio, A. : La Epigrafía romana de Itálica. Tesis Doctoral. Madrid, U. Complutense, 1985.

Christol, M. : "Un écho des jeux seculaires de 204 ap. C.", Révue d'études anciennes. 73. Bordeaux, U. de Bordeaux, 1971, págs. 124140.

CORELL VICENT, J. : “Dos inscripciones a Liber Pater procedentes de Montaña Frontera (Sagunt)" ARSE 20 (1985), págs. 25-30.

«El culto a Liber Pater en el sur del Conventus Tarraconensis según la Epigrafia", Actas Col.loqui d'Epigrafia. Tarragona, octubre 1988. En prensa.

Cumont, F. : Les religiones orientales dans le paganisme romaine. París, E. Leroux 1927.

Etienne, R. : Le culte impérial, dans la Peninsule ibérique d'Auguste à Diocletien. Paris, BEFAR 191. De Boccard, 1958.

Fernández Corrales, J., y Redondo Rodríguez, J. A. : “Liber Pater et Libera: nuevo hallazgo en Zorita (Cáceres)", Anuario de Estudios Filológicos VII (1985). Cáceres, págs. 67-73.

FERNÁNDEZ FUSTER, L. : “La fórmula "ex visu» en la Epigrafía hispánica", AEA 23 (1950), págs. 279-291.

FITA, F. : "Nuevas inscripciones romanas en la provincia de Jaén», $B R A H$ 39 (1901), págs. 420-429.

FLetCheR, D., y SILGo, L. : “Repertorio de inscripciones ibéricas procedentes de Sagunto (Valencia)», ARSE 22 (1987), págs. 44-45.

Garcia SAnz, O. : Baco en Hispania. Economía y Religión, a través de las fuentes epigráficas, arqueológicas y literarias. Tesis Doctoral. Madrid, U. Complutense, 1990.

Gómez Moreno, M. : Provincia de León (1906-1908). Catálogo Monumental de España. Madrid, M. ${ }^{\circ}$ de Inst. Pública y B. Artes, 1925.

Hoyo CALLEJA, J. del : La importancia de la mujer hispanorromana en la Tarraconensis y Lusitania a la luz de los documentos epigráficos. Tesis Doctoral. Madrid, U. Complutense, 1987.

Liber Pater dans l'épigraphie hispanique, Rélations entre Viticulture et le culte au dieux".

Col. Archéologie de la Vigne et du Vin. París, Centre de Recherches 
A. Piganiol, 1988. En prensa.

"La relación culto/estrato social en la Hispania romana», Actas Col.loqui d'Epigrafía. Tarragona, octubre 1988. En prensa.

Leite De Vasconcelos, J. : Nuevas divinidades de Lusitania. Lisboa, Imprenta Nacional, 1913.

MAÑANes PéRez, T. : Epigrafía y Numismática de Astorga romana y su entorno. Salamanca, U. de Salamanca, 1982.

Millán Gónzalez, J. : Sobre las aras del Santuario de Donón, supuestamente dedicadas a Liber. Vigo 1978.

Oliver FolX, A. : "Grafitos ibéricos provecentes de la Montaña Frontera (Sagunto)", Saguntun 20. Sangunto (1986), págs. 117-122.

PAStor MuÑoz, M.: "La religión romana en el Conventus Asturum», Hispania 36. CSIC. Madrid 1976, págs. 489-524.

REDONDO RODR'IGUEZ, J. A. : "Algunas consideraciones acerca del culto a Liber Pater en la Alta Extremadura", Col. $H^{a}{ }^{a}$ Antigua de Andalucía I. Córdoba (1988). En prensa.

Nuevos epígrafes romanos en Extremadura», Anuario de Estudios Filológicos XI (1988), págs. 325-313.

Ribelles, B. : «Restos de un templo de Baco», Diario de la Ciudad de Valencia 28/2 1820, págs. 253-265.

Roca Ribelles, F. : «Epigrafia latina saguntina», ARSE 23 (1988), págs. 79-83.

"Seis nuevas lápidas latinas de Sagunto", ARSE 18 (1983), págs. 13-17.

Rosco, J., y TeLLEZ, L. : “Liber-Libera», I Jorn. sobre manif. religiosas en Lusitania. Cáceres, U. de Extremadura, 1986, págs. 141-2.

Sánchez Abal, J. L., y Salas Martín, J. : "Catálogo epigráfico de Cáceres: nuevas aportaciones", Norba IV (1983). Cáceres, U. de Extremadura, págs. 263-276.

SILGo GaUCHO, L. : "La antroponimia ibérica de Sagunto», ARSE 23 (1988), págs. 68-73.

“lldutacon ¿divinidad ibérica o saguntina?, ARSE 21 (1986), págs. 17-19.

Solin, H. : Die Griechischen Personnamen in Rom. Ein Namebuch. Berlin, De Gruyter, 1982.

VAZQUEZ-HOYS, A. M. : "Algunas consideraciones sobre cultos locales en la Hispania romana", Memorias de $H^{2}{ }^{2}$ Ant. 5. U. de Oviedo (1981), págs. 41-50.

VIeIRA De Silva, A. : Epigrafia de Olisipo. Lisboa 1944.

VV. AA. : Fouilles de Conimbriga II. Épigraphie et Sculpture. Paris, De Boccard, 1976. 